\title{
Karyotypes of four species of Xenodontini snakes (Serpentes) and implications for taxonomy
}

\author{
Camila Falcione ${ }^{1,4}$, Alejandra Hernando 1 , Diego Andrés Barrasso ${ }^{2}$, Diego Omar Di Pietro ${ }^{3}$ \\ ${ }^{1}$ Laboratorio de Herpetología, Facultad de Ciencias Exactas y Naturales y Agrimensura, Universidad Nacional \\ del Nordeste, Av. Libertad 5470 (3400), Corrientes, Argentina \\ ${ }^{2}$ Instituto de Diversidad y Evolución Austral (CONICET), Boulevard A. Brown 2915 (U9120ACD), Puerto Madryn, \\ Chubut, Argentina \\ ${ }^{3}$ Sección Herpetología, División Zoología Vertebrados, Facultad de Ciencias Naturales y Museo, Universidad \\ Nacional de La Plata, Av. 122 y 60 s/n (B1900FWA) La Plata, Argentina \\ ${ }^{4}$ E-mail: camilafalcione@hotmail.com
}

Key words: karyosystematics, Lygophis, variability

\begin{abstract}
The karyotypes of four Xenodontini snake species, Lygophis dilepis, L. meridionalis, L. flavifrenatus and L. anomalus, are here described for the first time. We studied specimens from northeastern Argentina using conventional and silver (Ag-NOR) staining. While the typical ophidian karyotype is $2 \mathrm{n}=36$, we found that the karyotype of the studied species is $2 n=34$, with metacentric and submetacentric chromosome pairs. The AgNOR staining revealed that nucleolar organizer regions (NORs) are located on one pair of microchromosomes. In L. dilepis and L. anomalus the $4^{\text {th }}$ chromosome pair is heteromorphic, and we suggest that it might be considered as the ZW sex chromosome pair. The optimization of available karyological data on a molecular phylogenetic tree of the tribe Xenodontini shows that the diploid numbers $2 \mathrm{n}=28,30$ and 34 represent putative synapomorphy for Erythrolamprus, Xenodon and Lygophis, respectively. Our results provide new insights which fill gaps in our knowledge on the cytology in the genus Lygophis and identified a possible diagnostic character for the genus.
\end{abstract}

\section{Contents}

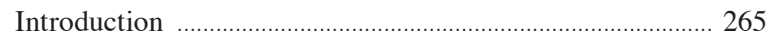

Materials and methods ………………………………….......... 267

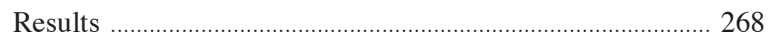

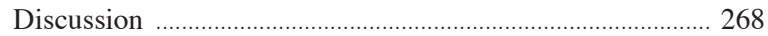

Acknowledgements ……..................................................... 271

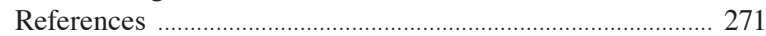

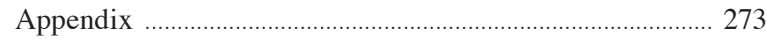

\section{Introduction}

In recent years, phylogenetic studies based on morphological and molecular data have resulted in modifications in the systematic and phylogenetic relationships of Serpentes (Zaher, 1999; Vidal et al., 2000, 2010;
Zaher et al., 2009; Grazziotin et al., 2012; Pyron et al., 2013). The monophyletic tribe Xenodontini (Vidal et al., 2000, 2010; Grazziotin et al., 2012) is one of the South American snake radiations comprising about 70 species (Uetz and Jirí, 2013). According to the classification considered the clade is included in the subfamily Xenodontinae into Dipsadidae (Zaher et al., 2009) or in the subfamily Dipsadinae into Colubridae (Pyron et al., 2013).

The Xenodontini (sensu Vidal et al., 2010 and Grazziotin et al., 2012) is composed by the genera Lygophis Fitzinger 1843, Erythrolamprus Boie 1826 and Xenodon Boie 1826, clade also recover in other phylogenetic analysis (Zaher et al., 2009; Pyron et al., 2013; see nomenclatural discussion in Curcio et al., 2009). The genus Lygophis was resurrected by Zaher et al. (2009), and confirmed by other studies (Vidal et al., 2010; Grazziotin et al., 2012; Pyron et al., 2013). Lygophis comprises eight species grouped in the 'anomalus' and the 'lineatus' morphological groups; with three and five species, respectively (Dixon, 1985, Michaud and Dixon, 1987).

The cytogenetics of the Xenodontini is poorly known. Chromosomal data are restricted to six Erythrolamprus species and four Xenodon species (Beçak, 1968; Beçak and Beçak, 1969; Beçak et al., 1971, 1975; Gutiérrez et al., 1984). Karyological information has been obtained using conventional cytological staining protocols. Localization of the nucleolar organizer regions (NORs) was only carried out on E. poecilogyrus schotti (Trajtengertz et al., 1995).

Although information is scarce, the Xenodontini appear to be a karyologically diverse tribe. In fact, four diploid numbers $(2 \mathrm{n}=28,30,32,34)$, eight karyotype 
Table 1. Centromeric index (CI) and chromosome type of macrochromosome pairs (1-8) of Lygophis snakes analyzed in this study. a, the heteromorphic pair. Abbreviations: $\mathrm{M}=$ metacentric, $\mathrm{SM}=$ submetacentric.

\begin{tabular}{|c|c|c|c|c|c|c|c|c|c|c|c|}
\hline Chromosome pair number & Sex & & 1 & 2 & 3 & $4^{\mathrm{a}}$ & & 5 & 6 & 7 & 8 \\
\hline \multirow[t]{3}{*}{ L. flavifrenatus } & \multirow[t]{3}{*}{ o } & \multirow[t]{2}{*}{$\mathrm{CI}$} & 47.62 & 46.37 & 45.56 & & 46.68 & 46.99 & 44.90 & 45.69 \\
\hline & & & \pm 1.08 & \pm 2.23 & \pm 2.98 & \multicolumn{2}{|l|}{ \pm 1.99} & \pm 1.56 & \pm 1.90 & \pm 1.92 & \pm 1.69 \\
\hline & & Type & M & M & M & \multicolumn{2}{|l|}{ M } & M & M & M & M \\
\hline \multirow[t]{6}{*}{ L. dilepis } & \multirow[t]{3}{*}{ q } & \multirow[t]{2}{*}{ CI } & 47.19 & 35.71 & 47.76 & 47.10 & 34.04 & 47.15 & 47.51 & 45.35 & 46.61 \\
\hline & & & \pm 3.51 & \pm 2.44 & \pm 0.97 & \pm 1.49 & \pm 2.11 & \pm 1.13 & \pm 1.21 & \pm 2.22 & \pm 1.53 \\
\hline & & Type & M & $\mathrm{SM} / \mathrm{M}$ & M & M & SM & M & M & M & $\mathrm{M}$ \\
\hline & \multirow[t]{3}{*}{$\hat{o}$} & $\mathrm{CI}$ & 47.30 & 35.95 & 47.77 & \multirow{2}{*}{\multicolumn{2}{|c|}{$\begin{array}{l}45.33 \\
\pm 2.27\end{array}$}} & 45.74 & 47.01 & 46.94 & 46.33 \\
\hline & & & \pm 2.63 & \pm 2.15 & \pm 1.09 & & & \pm 2.49 & \pm 2.23 & \pm 1.99 & \pm 1.46 \\
\hline & & Type & M & $\mathrm{SM} / \mathrm{M}$ & M & \multicolumn{2}{|l|}{ M } & M & M & M & M \\
\hline \multirow[t]{3}{*}{ L. meridionalis } & \multirow[t]{3}{*}{ q } & $\mathrm{CI}$ & 49.16 & 43.52 & 46.09 & 31.73 & 48.27 & 47.47 & 45.88 & 45.01 & 44.64 \\
\hline & & & \pm 0.45 & \pm 2.23 & \pm 0.77 & \pm 3.22 & \pm 1.42 & \pm 1.55 & \pm 2.31 & \pm 1.08 & \pm 2.40 \\
\hline & & Type & M & M & M & SM & M & M & M & M & M \\
\hline \multirow[t]{6}{*}{ L. anomalus } & \multirow[t]{3}{*}{ q } & $\mathrm{CI}$ & 48.94 & 44.05 & 45.49 & 42.59 & 33.10 & 43.16 & 42.26 & 40.73 & 47.64 \\
\hline & & & \pm 1.31 & \pm 0.67 & \pm 1.47 & \pm 0.49 & \pm 1.17 & \pm 0.33 & \pm 1.54 & \pm 1.86 & \pm 1.53 \\
\hline & & Type & M & M & M & M & SM & M & M & M & M \\
\hline & \multirow[t]{3}{*}{$\hat{0}$} & CI & 47.76 & 39.40 & 46.90 & \multirow{2}{*}{\multicolumn{2}{|c|}{$\begin{array}{l}46.43 \\
\pm 1.41\end{array}$}} & 45.05 & 31.85 & 41.37 & 38.43 \\
\hline & & & \pm 0.69 & \pm 1.09 & \pm 1.13 & & & \pm 1.91 & \pm 1.56 & \pm 1.40 & \pm 1.58 \\
\hline & & Type & M & $\mathrm{M}$ & M & \multicolumn{2}{|l|}{$\mathrm{M}$} & M & $\mathrm{SM}$ & M & $\mathrm{SM} / \mathrm{M}$ \\
\hline
\end{tabular}

Table 2. Intra and intergeneric variation in the diploid number, chromosome formula, and sex chromosome morphology in species of tribe Xenodontini. Abbreviations: $\mathrm{M}=$ macrochromosome, $\mathrm{m}=$ microchromosome.

\begin{tabular}{|c|c|c|c|c|c|}
\hline Species & $2 n$ & $\begin{array}{l}\text { Chromosome } \\
\text { formula }\end{array}$ & $\begin{array}{l}\text { Sex chromosome } \\
\text { Z }\end{array}$ & $\begin{array}{l}\text { morphology } \\
\text { W }\end{array}$ & Reference \\
\hline $\begin{array}{l}\text { Erythrolamprus aesculapii } \\
\text { venustissimun }\end{array}$ & 28 & $16+4+8(\widehat{o}, 9)$ & Metacentric & Submetacentric & Beçak et al., 1966; Beçak and Beçak, 1969 \\
\hline E. epinephelus & 28 & $16+4+8(\hat{0}$, 우 $)$ & - & & Gutiérrez et al., 1984 \\
\hline E. almadensis & 28 & $\begin{array}{l}27+1+0(\text { ( }) \\
28+0+0(\text { ( })^{\Uparrow}\end{array}$ & Metacentric & Acrocentric & Beçak et al., 1975 \\
\hline E. bizona & 28 & $18+2+8($ (q) & Submetacentric & Submetacentric & Gutiérrez et al., 1984 \\
\hline E. miliaris & 28 & $\begin{array}{l}19+1+8(\text { ( ) } \\
20+0+8\left({ }^{\pi}\right)\end{array}$ & Metacentric & Acrocentric & Beçak and Beçak, 1969 \\
\hline E. poecilogyrus schotti & 32 & - & - & & Beçak et al., 1971; Trajtengertz et al., 1995 \\
\hline Xenodon merremi & 30 & $16+0+14(\widehat{\jmath}, \stackrel{+}{)})$ & Metacentric & Metacentric & Beçak, 1968 \\
\hline$X$. neuwedii & 30 & $14+2+14(0 \hat{0}, 9)$ & Metacentric & Metacentric & Beçak and Beçak, 1969 \\
\hline$X$. severus & 30 & $14 \mathrm{M}+16 \mathrm{~m}$ & - & & Beçak et al., 1971 \\
\hline X. rabdocephalus & 34 & $14+8+12($ ๙,,+$)$ & Submetacentric & Metacentric & Gutiérrez et al., 1984 \\
\hline Lygophis anomalus & 34 & $16+0+18(\widehat{0},+9)$ & Metacentric & Submetacentric & This study \\
\hline L. dilepis & 34 & $16+0+18($ ơ, 9$)$ & Metacentric & Submetacentric & This study \\
\hline L. meridionalis & 34 & $16+0+18$ (ㅇ) & - & & This study \\
\hline L. flavifrenatus & 34 & $16+0+18\left(0^{7}\right)$ & - & & This study \\
\hline
\end{tabular}

formulas, the ZW sex determination system, and a remarkable intra- and inter-generic karyotypic variability were described by previous studies (Beçak, 1968; Beçak and Beçak, 1969; Beçak et al., 1971, 1975; Gutiérrez et al., 1984). In Erythrolamprus, one karyotype $2 \mathrm{n}=32$ and five karyotypes $2 \mathrm{n}=28$ which differ in micro- and macro-chromosome number and macrochromosomes morphology have been found (Beçak and Beçak, 1969; Beçak et al., 1971, 1975; Gutiérrez et al., 1984). Three species of Xenodon have the same diploid number of $2 \mathrm{n}=30$ including 14 or 16 macrochromosomes and microchromosomes, while X. rab- 


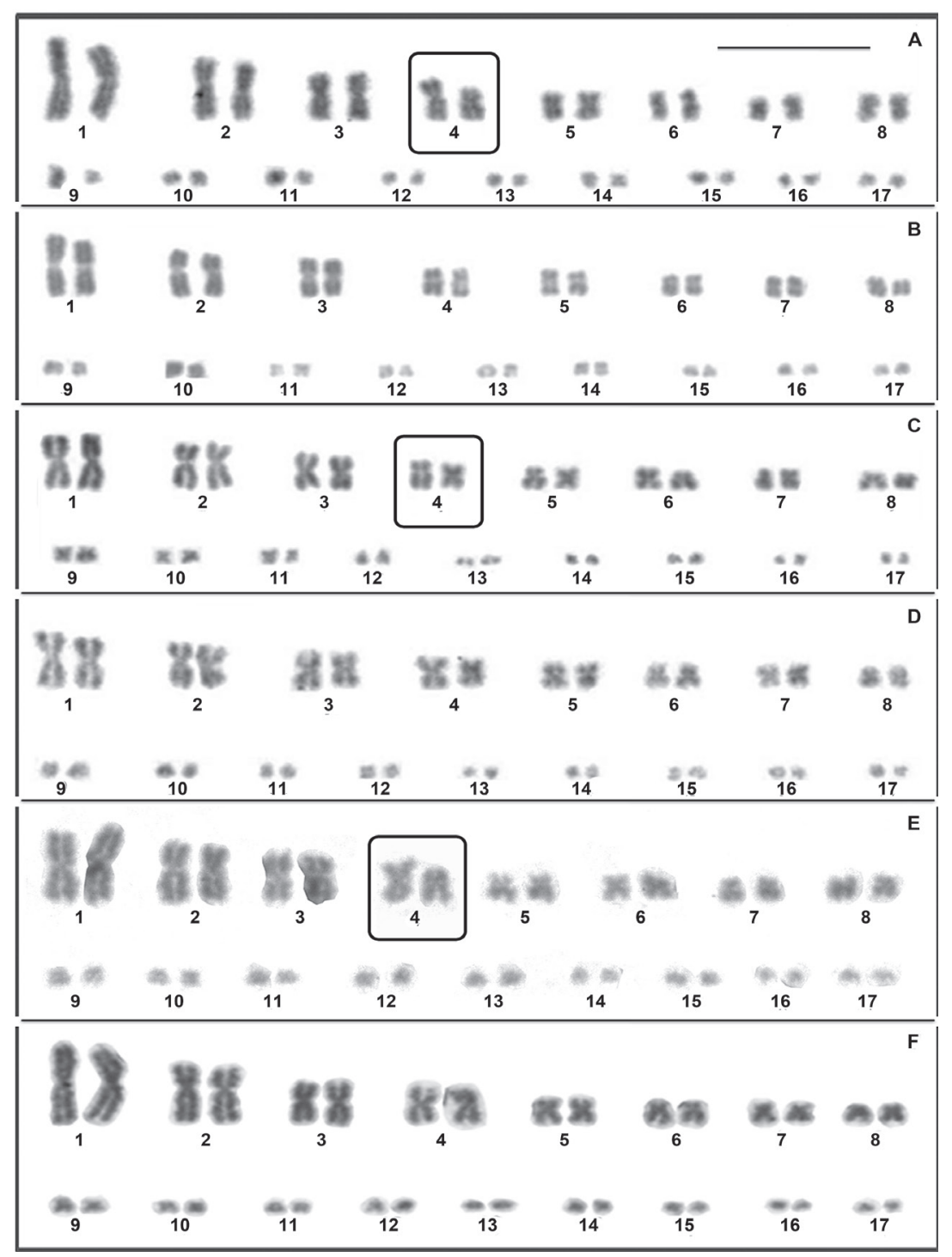

Fig. 1. Mitotic karyotypes of four Lygophis species. A) Lygophis dilepis (female), B) L. dilepis (male), C) L. meridionalis (female), D) L. flavifrenatus (male), E) L. anomalus (female) and F) L. anomalus (male). Rounded boxes illustrate the heteromorphic pair. Scale bar $=10 \mu \mathrm{m}$. docephalus $(2 \mathrm{n}=34)$ exhibits 22 macro-chromosomes and a reduced micro-chromosome complement of 12 (Beçak, 1968; Beçak and Beçak, 1969; Beçak et al., 1971; Gutiérrez et al., 1984).

Cytogenetic characters can be used to infer evolutionary relationships if they are analysed together with other independent characters (morphological, molecular, immunological, isozyme) (Sites and Reed, 1994). Indeed, such an approach has been demonstrated to be important to understand the diversity and evolution in snakes (Oguiura et al., 2009; Mezzasalma et al., 2014).

Hitherto no cytological characters were known for the genus Lygophis. To fill this information vacuum, we documented the karyotype and the location of
Ag-NORs in four species: L. dilepis Cope, 1862, L. meridionalis (Schenkel, 1902) and L. flavifrenatus Cope, 1862 (all belonging to the 'lineatus' group sensu Michaud and Dixon, 1987) and L. anomalus (Günther, 1858) (belonging to the 'anomalus' group sensu Dixon, 1985).

\section{Material and methods}

Chromosome analyses were carried out in males and females of L. flavifrenatus, L. meridionalis, L. dilepis and L. anomalus (see details in the Appendix). Voucher specimens are deposited in the Colección Herpetológi- 


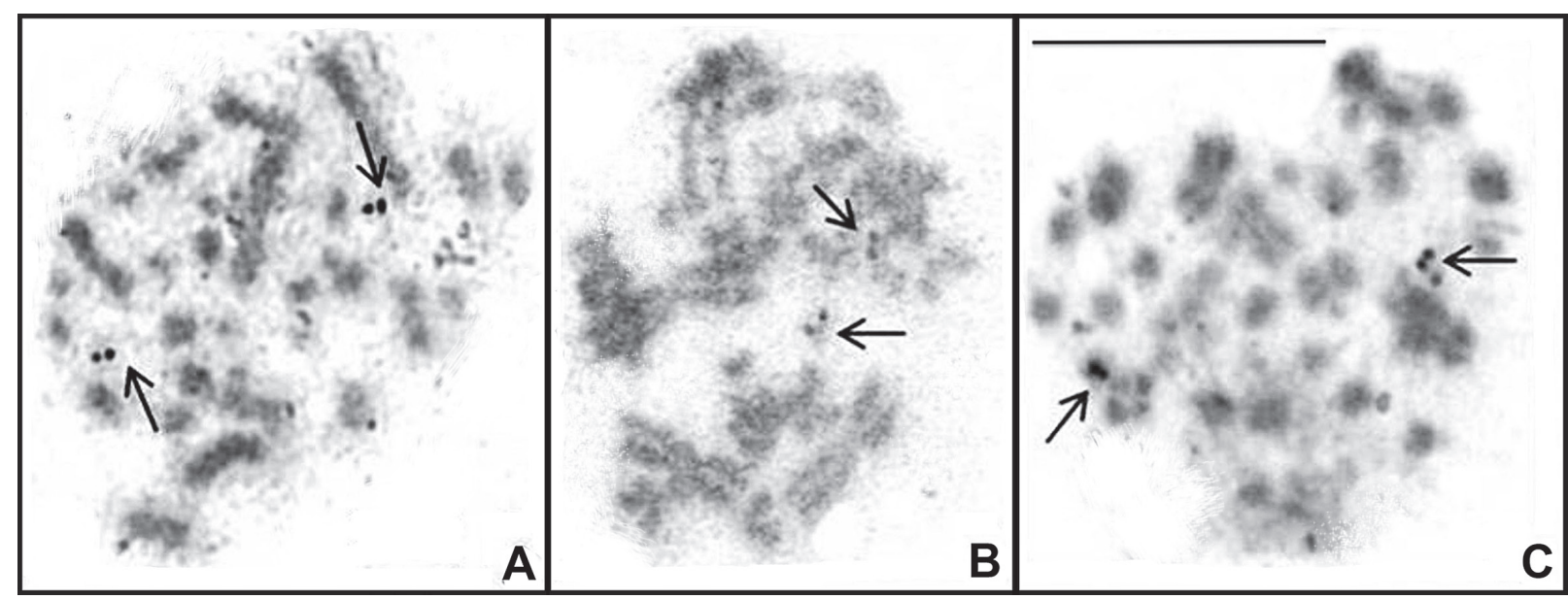

Fig. 2. Metaphases after silver staining (Ag-NORs). Arrows indicate the NORs on a pair of microchromosomes. A) Lygophis dilepis, B) L. meridionalis, C) L. flavifrenatus. Scale bar $=10 \mu \mathrm{m}$.

ca de la Universidad Nacional del Nordeste (UNNEC), Corrientes, Argentina.

Four hours prior to animal dissection, specimens were injected intraperitoneally with $0.1 \%$ colchicine ( $1 \mathrm{ml} / 100 \mathrm{~g}$ body weight). The euthanasia method proposed by Beaupre et al. (2004) was used. Chromosomes were obtained from intestinal epithelium by dispersion of cells on the hot stage. Chromosome preparations were stained conventionally using a $10 \%$ Giemsa solution at $\mathrm{pH}$ 6.8. The NORs were detected using the silver staining (Ag-NOR) technique applied by Howell and Black (1980). The Ag-NORs banding staining was performed only for species which provided a sufficient number and quality of metaphase plate.

To calculate the centromeric index (CI), the arms of macrochromosomes were measured on ten metaphase plates of each specimen using the software MicroMeasure version 3.3 (Reeves and Tear, 2000). The chromosomal formula was determined following Peccinini-Seale (1981): $(2 \mathrm{n}=\mathrm{I}+\mathrm{II}+\mathrm{III})$, with $\mathrm{I}=$ metacentric or submetacentric macrochromosomes, II = telocentric or subtelocentric macrochromosomes and III = microchromosomes. Chromosomes that measured around 1 micron $(\mu \mathrm{m})$ were classified as microchromosomes.

To reconstruct karyotype evolution within the Xenodontini clade, the diploid number (from our results and from the literature) of Xenodontini species was optimized on the most recent phylogenetic hypothesis of Squamata by Pyron et al. (2013) using the parsimony criterion with TNT software (Goloboff et al.,
2008).

\section{Results}

The diploid chromosome complements of $L$.dilepis, $L$. meridionalis, L. flavifrenatus and L. anomalus were similar (Fig. 1A-F). The karyotype was $2 \mathrm{n}=34(16+$ $0+18$ ) and consisted of eight pairs of metacentric or submetacentric macrochromosomes, gradually decreasing in size (Table 1) and nine pairs of microchromosomes. No secondary constrictions were observed.

In females of $L$. dilepis, $L$. meridionalis and $L$. anomalus the $4^{\text {th }}$ chromosomal pair was heteromorphic. In L. dilepis and L. anomalus, the larger element was metacentric and the smaller submetacentric (Fig. 1A, E). In L. meridionalis, the submetacentric corresponded to the larger chromosome and the metacentric to the smaller (Fig. 1C). In males of L.dilepis, L. flavifrenatus and L. anomalus, the homologous of pair 4 were metacentric and of similar size (Fig. 1B, D, F).

The NORs were detected on one pair of microchromosomes in L. dilepis, L. flavifrenatus, L. meridionalis (Fig. 2A-C).

\section{Discussion}

In snakes, chromosome numbers range from $2 \mathrm{n}=24$ to $2 \mathrm{n}=52$, with $2 \mathrm{n}=36$ being the most frequent number (16 macrochromosomes and 20 microchromo- 
somes) (Beçak and Beçak, 1969; Oguiura et al., 2009). Karyotypes differing from this formula and with the chromosome number varying from $2 \mathrm{n}=28$ to $2 \mathrm{n}=34$ have been documented in 14 Xenodontini species belonging to the genera Erythrolamprus and Xenodon, as reported by several studies (Beçak, 1968; Beçak and Beçak, 1969; Beçak et al., 1971; 1975; Gutiérrez et al., 1984), and to the genus Lygophis, as here studied (Table 2).

Five Erythrolamprus species share the diploid number $2 \mathrm{n}=28$ but with variations in the number of bi- and uniarmed macro- and microchromosomes. Erythrolamprus aesculapii venustissimun, E. epinephelus, E. bizona and E. miliaris have karyotypes with 20 macrochromosomes and eight microchromosomes whereas 28 macrochromosomes and no microchromosomes were described in E. almadensis (Beçak and Beçak, 1969; Beçak et al., 1975; Gutiérrez et al., 1984). When considering all currently known chromosomal data for Erythrolamprus (Table 2), two out of the 10 pairs of macrochromosome are uniarmed in E. aesculapii venustissimun (pairs 9 and 10) and E. epinephelus (pairs 6 and 9) and one in E. bizona (pair 6). In $E$. miliaris and E. almadensis all macrochromosomes are biarmed. In E. poecilogyrus schotti, $2 \mathrm{n}=32$, and there is no clear distinction between macro- and microchromosomes (Beçak et al., 1971; Trajtengertz et al., 1995). In the genus Xenodon, X. merremi and X. newiedii have a similar $2 \mathrm{n}=30$ karyotype with eight macrochromosome pairs and seven microchromosome pairs (Beçak, 1968; Beçak and Beçak, 1969). Although X. severus also exhibits $2 \mathrm{n}=30$, it has seven macro- and eight microchromosomes (Beçak et al., 1971). According to Beçak et al. (1971), in the karyotype of $X$. severus, a translocation that occurred between macrochromosomes can explain the numeric differences in the karyotypes of Xenodon species. Moreover, X. rabdocephalus exhibits the highest diploid number known in Xenodontini $(2 \mathrm{n}=34)$. Its karyotype includes 22 macrochromosome pairs of which 14 are biarmed and 8 uniarmed, coupled to 12 microchromosomes (Gutiérrez et al., 1984). The chromosome complement of $X$. rabdocephalus has more uniarmed macrochromosome pairs but one or two fewer microchromosome pairs than the karyotype of $2 \mathrm{n}=30$ Xenodon species (Beçak, 1968; Beçak and Beçak, 1969; Beçak et al., 1971).

Lygophis dilepis, L. meridionalis, L. flavifrenatus and $L$. anomalus have a similar karyotype consisting of 34 chromosomes (16 biarmed macrochromosome pairs and 18 microchromosomes). Although $2 \mathrm{n}=34$ has also been reported for X. rabdocephalus, differences can be noted between these two taxa, since the Lygophis karyotype consists of eight pairs of biarmed macrochromosomes and three additional microchromosomes pairs when compared with the karyotype of X. rabdocephalus.

Considering that the karyotype $2 \mathrm{n}=36$ (16 macrochromosomes and 20 microchromosomes) occurred in the common ancestor of snakes (Oguiura et al., 2009), several mechanisms have been proposed to explain chromosomal evolution of Xenodontini. In Erythrolamprus $(2 \mathrm{n}=28$ and 32$)$ and Xenodon $(2 \mathrm{n}=30$ and $34)$ the reduction in the diploid number resulted from unequal translocations between macro- and microchromosomes (Gutiérrez et al., 1984) and Robertsonian fusions of microchromosomes (Beçak and Beçak, 1969). Additional centric fissions of macrochromosomes probably played an important role in the differentiation of Xenodon karyotypes (Gutiérrez et al., 1984). On the other hand, we suggest that chromosomal inversion and reduction in the number of microchromosomes were involved in the karyotype evolution of Lygophis $(2 \mathrm{n}=34)$. Lower microchromosomes number also have observed in others Dipsadidae snakes (Hydrodynastes: $2 \mathrm{n}=24$, Philodryas serra: $2 \mathrm{n}=28$, Thamnodynastes strigatus: $2 \mathrm{n}=32$ and T. hypoconia: 2n = 34) (Beçak and Beçak, 1969).

The Boidae genera Eryx, Acrantophis and Sanzinia $(2 \mathrm{n}=34)$ and Micrurus species (Elapidae) from Central America $(2 n=26$ to $2 n=34)$ tend to reduce the chromosome number probably due to fusion microchromosomes processes (Beçak and Beçak, 1969; Gutiérrez and Bolaños, 1979; Mengden and Stock, 1980; Oguiura et al., 2009). From an ancestral karyotype $2 n=48$ in Pseudoxyrhophiinae (Lamprophiidae), the chromosomal diversification and reduction of the chromosome number may have occurred as a result of translocations of microchromosomes to macrochromosomes, tandem fusions and centric fissions and fusions (Mezzasalma et al., 2014). Recently, it has been proposed that during diversification of Squamata the decrease in number of microchromosomes may have occurred by repeated fusions between macro- and/or other micro-chromosomes (Uno et al., 2012).

The presence of ZW sex chromosomes in the $4^{\text {th }}$ position was reported in many colubrids, elapids, and viperids (Beçak and Beçak, 1969; Singh, 1972; Gutiérrez et al., 1979; Mengden and Stock, 1980; Beçak and Beçak, 1981; Ota, 1999; Aprea et al., 2003, 2006) and has been considered a putative synapomorphy of the superfamily Colubroidea (Oguiura et al., 2009). The 


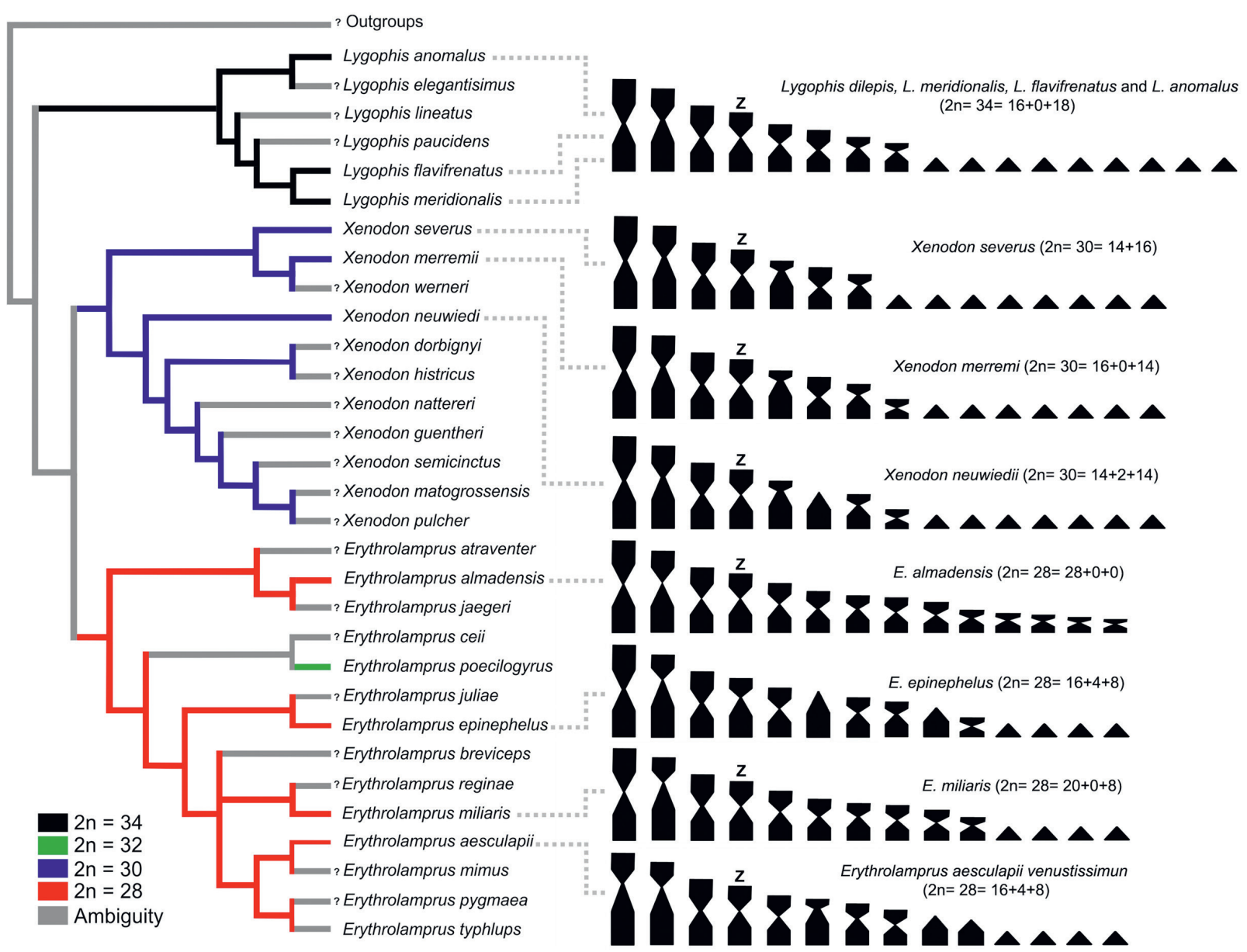

Fig. 3. Diploid number optimization within Xenodontini clade based on the molecular phylogenetic hypothesis presented by Pyron et al. (2013). The outgroup consisted of the sister clade (Uromacer catesbyi + U.frenatus + U. oxyrhynchus). The gray branches represent ambiguity and the question symbols (?) the missing entries. On the right are the karyograms of the included species for which chromosomal information is available.

degree of heteromorphy of the $\mathrm{ZW}$ chromosomes is variable; they can be similar morphologically or differ in shape and/or size and in heterochromatin distribution (Beçak and Beçak, 1969; Singh, 1972; Mengden and Stock, 1980; Olmo, 1986; Oguiura et al., 2009). A ZZ:ZW system among Xenodontini was also reported for X. merremi, X. neuwedii, X. rabdocephalus, E. almadensis, E. miliaris and E. bizona (Table 2) (Beçak, 1968; Beçak and Beçak, 1969; Beçak et al., 1975; Gutiérrez et al., 1984).

In $L$. dilepis and L. anomalus females metaphases exhibited a metacentric/submetacentric heteromorphic $4^{\text {th }}$ pair, and the respective males possessed two homomorphic metacentric chromosomes on the same posi- tion. Although based on the analysis of Giemsa-stained metaphases, these observations lead us to suggest that the $4^{\text {th }}$ pair could be related to the ZW system of sex determination. Beçak and Beçak (1969) and Matsubara et al. (2006) suggested that, in snakes, heteromorphic sex chromosomes are the result of pericentric inversions, heterochromatinization and deletion of euchromatic regions.

Lygophis dilepis, L. flavifrenatus and L. meridionalis have a similar NORs location (one pair of microchromosomes). The same position has been reported for Xenodontini in E. poecilogyrus schotti (Trajtengertz et al., 1995) and in Old and New World snakes (Camper and Hanks, 1995; Aprea et al., 2006). As such, 
this number and location of NORs appears be prevalent in Serpentes (Camper and Hanks, 1995; Aprea et al., 2006). However, in Xenodontini, further studies are necessary to understand the distribution of this character within this group.

Of the thirteen species of the Xenodontini tribe cytogenetically described to date eleven are included in the phylogeny proposed by Pyron et al. (2013) and the available data only allow evaluation of the chromosome number and morphology. Our optimization show that diploid numbers represent putative synapomorphies for each genus (Fig. 3): Lygophis $2 \mathrm{n}=34$, Xenodon $2 \mathrm{n}=30$ and Erythrolamprus $2 \mathrm{n}=28$ (with an increase in E. poecilogyrus to $2 \mathrm{n}=32$ ). Unfortunately, we have no karyological data for the sister clade (Uromacer catesbyi $+U$. frenatus $+U$. oxyrhynchus) and for this reason it was not possible to evaluate the ancestral diploid number of the study group.

This study provides new data on the karyology of the Xenodontini. Yet, more studies on the karyology as well as on phylogenetic relationships in the Xenodontini species are necessary. Moreover, karyological information is available for three species that have not yet been included in molecular phylogenetic studies: $E$. bizona $(2 \mathrm{n}=28)$, L. dilepis $(2 \mathrm{n}=34)$, and X. rabdocephalus $(2 \mathrm{n}=34)$. Consequently, this information could not be optimized.

Although based on only four species, our study reinforce that there is remarkable variation in the karyotypes of Xenodontini. The karyotype $2 \mathrm{n}=34=16+$ $0+18$ is shared among the studied Lygophis species and could thus be a diagnostic character for the genus. Increasing the taxonomic sampling in combination with the analysis of the banding patterns will allow us to further elucidate chromosomal evolution in Xenodontini.

\section{Acknowledgements}

We thank Dirección de Recursos Naturales of the Corrientes Province (Argentina) and Dirección de Fauna y Parques of the Formosa Province (Argentina) for providing collecting permits, Brigitte Marazzi for constructive comments and language review, Rodrigo Cajade for valuable suggestions and comments to this manuscript, José Augusto Ruiz García, Lucila Curi and María Teresa Sandoval for help us with the images. This work was supported by the Consejo Nacional de Investigaciones Científicas y Técnicas (CONICET), Argentina; and Secretaría General de Ciencia y Técnica, Universidad Nacional del Nordeste (SGCyT-UNNE), Argentina. We also wish thank to the two anonymous reviewers for their helpful comments.

\section{References}

Aprea G, Odierna G, Andreone F, Glaw F, Vences M. 2003. Unusual karyotype in the Malagasy colubrid snake Mimophis mahfalensis. Amphibia-Reptilia 24: 215-219.

Aprea G, Gentilli A, Zuffi MAL, Odierna G. 2006. The karyology of Vipera aspis, V. atra, V. hugyi, and Cerastesvipera. Amphibia-Reptilia 27: 113-119.

Beaupre SB, Jacobson ER, Lillywhite HB, Zamudio K. 2004. Guidelines for use of amphibians and reptiles in field and laboratory research, 2nd Edition. Revised by the Herpetological Animal Care and Use Committee (HACC) of the American Society of Ichthyologists and Herpetologists, Lawrence, Kansas.

Beçak W. 1968. Karyotypes, sex chromosomes and chromosomal evolution in snakes. Pp. 53-95 in: Bucherl W, Buckley E, Deulofeu V, eds, Venomous Animals and their Venoms. Vol. I. Academic Press, New York.

Beçak W, Beçak ML. 1969. Cytotaxonomy and chromosomal evolution in Serpentes. Cytogenetics 8: 247-262.

Beçak W, Carneiro SM, Beçak ML. 1971. Cariologia comparada em seis especies da colubrídeos (Serpentes). Ciencia $e$ Cultura 23: 123.

Beçak ML, Beçak W, Chen TR, Shoffner RN. 1975. Chromosome Atlas: Fish, Amphibians, Reptiles and Birds. Vol. 3. Benirschke K, Hsu TC, eds. Springer-Verlag. Berlin.

Beçak W, Beçak ML. 1981. Behaviour of the ZW Sex Bivalent in the Snake Bothrops jararaca. Chromosoma 83: 289-293.

Camper DJ, Hanks BG. 1995. Variation in the Nucleolus Organizer Region among New World Snakes. Journal of Herpetology 29: 468-471.

Curcio FF, Piacentini V, Fernandes DS. 2009. On the status of the snake genera Erythrolamprus Boie, Liophis Wagler and Lygophis Fitzinger (Serpentes, Xenodontinae). Zootaxa 2173: 66-68.

Dixon JR. 1985. A review of Liophis anomalus and Liophis elegantissimus, and the description of a new species (Serpentes: Colubridae). Copeia 1985: 565-573.

Goloboff PA, Farris JS, Nixon KC. 2008. TNT, a free program for phylogenetic analysis. Cladistics 24: 1-13.

Grazziotin FG, Zaher H, Murphy RW, Scrocchi G, Benavides MA, Zhang YP, Bonatto SL. 2012. Molecular phylogeny of the New World Dipsadidae (Serpentes: Colubroidea): a reappraisal. Cladistics 28: 437-459.

Gutiérrez JM, Bolaños R. 1979. Cariotipos de las principales serpientes coral (Elapidae: Micrurus) de Costa Rica. Revista de Biología Tropical 27: 57-73.

Gutiérrez JM, Taylor RT, Bolaños R. 1979. Cariotipos de diez especies de serpientes costarricenses de la familia Viperidae. Revista de Biología Tropical 27: 309-319.

Gutiérrez JM, Solórzano A, Cerdas L. 1984. Estudios cariológicos de cinco especies de serpientes costarricenses de la familia Colubridae. Revista de Biología Tropical 32: 263-267.

Howell WM, Black DA. 1980. Controlled silver-staining of nucleolus organizer regions with a protective colloidal developer: a 1-step method. Experientia 3: 1014-1015.

Matsubara K, Tarui H, Toriba M, Yamada K, Nishida-Umehara C, Agata K, Matsuda Y. 2006. Evidence for different origin of sex chromosomes in snakes, birds, and mammals and step-wise differentiation of snake sex chromosomes. Proceedings of the National Academy of Sciences of the United States of America 103: 18190-18195. 
Mengden GA, Stock D. 1980. Chromosomal evolution in Serpentes; a comparison of $\mathrm{G}$ and $\mathrm{C}$ chromosome patterns of some colubrid and boid genera. Chromosoma 79: 52-61.

Mezzasalma M, Andreone F, Branch WR, Glaw F, Guarino FM, Nagy ZT, Odierna G, Aprea G. 2014. Chromosome evolution in pseudoxyrhophiine snakes from Madagascar: a wide range of karyotypic variability. Biological Journal of the Linnean Society 112: 450-460.

Michaud EJ, Dixon JR. 1987. Taxonomic revision of the Liophis lineatus complex (Reptilia: Colubridae) of Central and South America. Milwaukee Public Museum Contributions in Biology and Geology 71: 1-26.

Oguiura N, Ferrarezzi H, Batistic RF. 2009.Cytogenetics and molecular data in snakes: a phylogenetic approach. Cytogenetics and Genome Research 127: 128-142.

Olmo E. 1986. A. Reptilia. Pp. 1-100 in: John B, ed., Animal cytogenetics, Vol. 4: Chordata 3. Gebrüder Bornträger, Berlin.

Olmo E, Signorino G. 2005. Chromorep: a reptile chromosomes database. Accesible at http://193.206.118.100/professori/chromorep.pdf. Accessed: February 2015.

Ota H. 1999. Karyotype of Pareas iwasakii: The first chromosomal description of a Pareatine snake (Colubridae). Japanese Journal of Herpetology 18: 16-18.

Peccinini-Seale D. 1981. New developments in vertebrate cytotaxonomy. IV. Cytogenetic studies in reptiles. Genetica 56: 123-148.

Pyron RA, Burbrink FT, Wiens JJ. 2013. A phylogeny and revised classification of Squamata, including 4161 species of lizards and snakes. BMC Evolutionary Biology 13: 93.

Reeves A, Tear J. 2000. MicroMeasure for Windows, version 3.3. Available at: http://www.colostate.edu/Depts/Biology/MicroMeasure.

Singh L. 1972. Evolution of karyotypes in snakes. Chromosoma 38: 185-236.

Sites JW, Reed K. 1994. Chromosomal evolution, speciation, and systematics: some relevant issues. Herpetologica 50: 237-249.
Trajtengertz I, Beçak ML, Ruiz IR. 1995. Ribosomal cistrons in Bothrops neuwiedi (Serpentes) subspecies from Brazil. Genome 38: 601-606.

Uetz P, Jirí H. 2013. The Reptile Database. Accessible at http:// www.reptile-database.org/. [accessed 1 April 2015]

Uno Y, Nishida C, Tarui H, Ishishita S, Takagi C, Nishimura O, Ishijima J, Ota H, Kosaka A, Matsubara K, Murakami Y, Kuratani S, Ueno N, Agata K, Matsuda Y. 2012. Inference of the protokaryotypes of amniotes and tetrapods and the evolutionary processes of microchromosomes from comparative gene mapping. PLoS ONE 7: e53027.

Vidal N, Kindl SG, Wong A, Hedges SB. 2000. Phylogenetic relationships of Xenodontine snakes inferred from $12 \mathrm{~s}$ and $16 \mathrm{~s}$ ribosomal RNA sequences. Molecular Phylogenetics and Evolution 14: 389-402.

Vidal N, Dewynter MI, Gower DJ. 2010. Dissecting the major American snake radiation: A molecular phylogeny of the Dipsadidae Bonaparte (Serpentes, Caenophidia). Comptes Rendus Biologies 333: 48-55.

Zaher H. 1999. Hemipenial morphology of the South American xenodontine snakes, with a proposal for a monophyletic Xenodontinae and a reappraisal of colubroid hemipenes. American Museum of Natural History 240: 1-168.

Zaher H, Grazziotin FG, Cadle JE, Murphy RW, Moura-Leite JC, Bonatto SL. 2009. Molecular phylogeny of advanced snakes (Serpentes, Caenophidia) with an emphasis on South American Xenodontines: a revised classification and descriptions of new taxa. Papéis Avulsos de Zoologia 28: 1-23.

Received: 29 July 2015

Revised and accepted: 27 November 2015

Published online: 28 July 2016

Editor: J. van Rooijen 


\section{Appendix}

Species names, sex, collection numbers, and localities of specimens of Lygophis sampled in this study. UNNEC $=$ Colección Herpetológica de la Universidad Nacional del Nordeste, Corrientes, Argentina.

Lygophis anomalus $(\mathrm{n}=5)$ : UNNEC-13001 () Paso

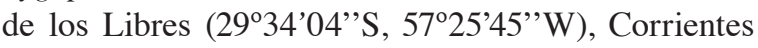
province, Argentina; UNNEC-13002 (\$) La Cruz (29 8'21''S, 56 52'35'”W), Corrientes province, Argentina; UNNEC-11047 (ઠ) Mercedes (2841’22”S, $\left.57^{\circ} 28^{\prime} 32^{\prime \prime} \mathrm{W}\right)$, Corrientes province, Argentina; UN-

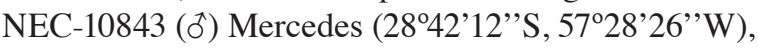
Corrientes province, Argentina; UNNEC-11046 (q) Medanos (3325'54''S, 59 04'17' W), Entre Rios province, Argentina.

Lygophis dilepis $(\mathrm{n}=6)$ : UNNEC-09736 (ઠ) Fontana

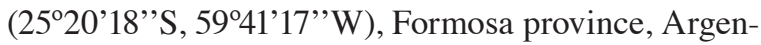

tina; UNNEC-10102 (ฮึ) Corrientes Capital (27²8' 09' S, 58 46'56' 'W), Corrientes province, Argentina; UNNEC-10204 (\%), UNNEC-10211 ( $($ ), and UNNEC-10212 ( + ) Paraje Perichón $\left(27^{\circ} 25^{\prime} 45^{\prime \prime}\right.$ 'S, 58 44 ' $45^{\prime \prime} \mathrm{W}$ ), Corrientes province, Argentina; UNNEC11831 (o) Calchaquí (2957'55’'S, 60¹9’49’'W), Santa Fé province, Argentina.

Lygophis flavifrenatus $(\mathrm{n}=2)$ : UNNEC-11013 (đ̋) San Roque (28'52'37''S, 58²8'09''W), Corrientes province, Argentina; UNNEC-11263 (ð) Corrientes Capital $\left(27^{\circ} 28^{\prime} 09^{\prime \prime} \mathrm{S}, 58^{\circ} 46^{\prime} 56^{\prime \prime} \mathrm{W}\right)$, Corrientes province, Argentina.

Lygophis meridionalis $(\mathrm{n}=2)$ : UNNEC-10209 () Isla Apipé (2731'12''S, 56 44'32'W), Corrientes province, Argentina; UNNEC-11263 (q) Concepción (28²3’01’'S, 57 $51^{\circ} 57^{\prime}$ 'W), Corrientes province, Argentina. 